\title{
CMA votes for review of medical liability system
}

\author{
Cite as: CMAJ 2017 September 11;189:E1153. doi: 10.1503/cmaj.1095486
}

Posted on cmajnews.com on Aug. 22, 2017.

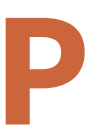

hysicians want the Canadian Medical Association (CMA) to review Canada's medical liability system and explore other models of protecting patients and physicians that may be more affordable. Doctors voted $79 \%$ in favour of a review at the CMA's annual general council in Quebec City.

"Recent increases in settlements have lessened the affordability of coverage, particularly for some rural specialists," said Dr. Andrew Clarke of British Columbia, who put forward the motion for the review. "This situation has become so acute in some parts of British Columbia that segments of the rural population are in danger of losing timely access to the specialty of obstetric care."

Dr. Hartley Stern of Ontario defended the current medical liability system, saying it was "the best for Canada," while acknowledging there is room for improvement. Stern is the CEO of the Canadian Medical Protective Association (CMPA), which "provides professional liability protection for Canadian physicians in the form of advice and legal assistance."

Stern said a similar review is already underway in Ontario, which may produce recommendations to decrease costs for doctors and patients. When the Ontario government releases its report, the CMPA intends to work with other provinces to ensure they also benefit from any recommendations.

"The CMPA supports a review of the medical liability system, with the hope that the goal of such a review is to make the current system better for patients and for physicians, and not to replace it with something risky and untried," he said.

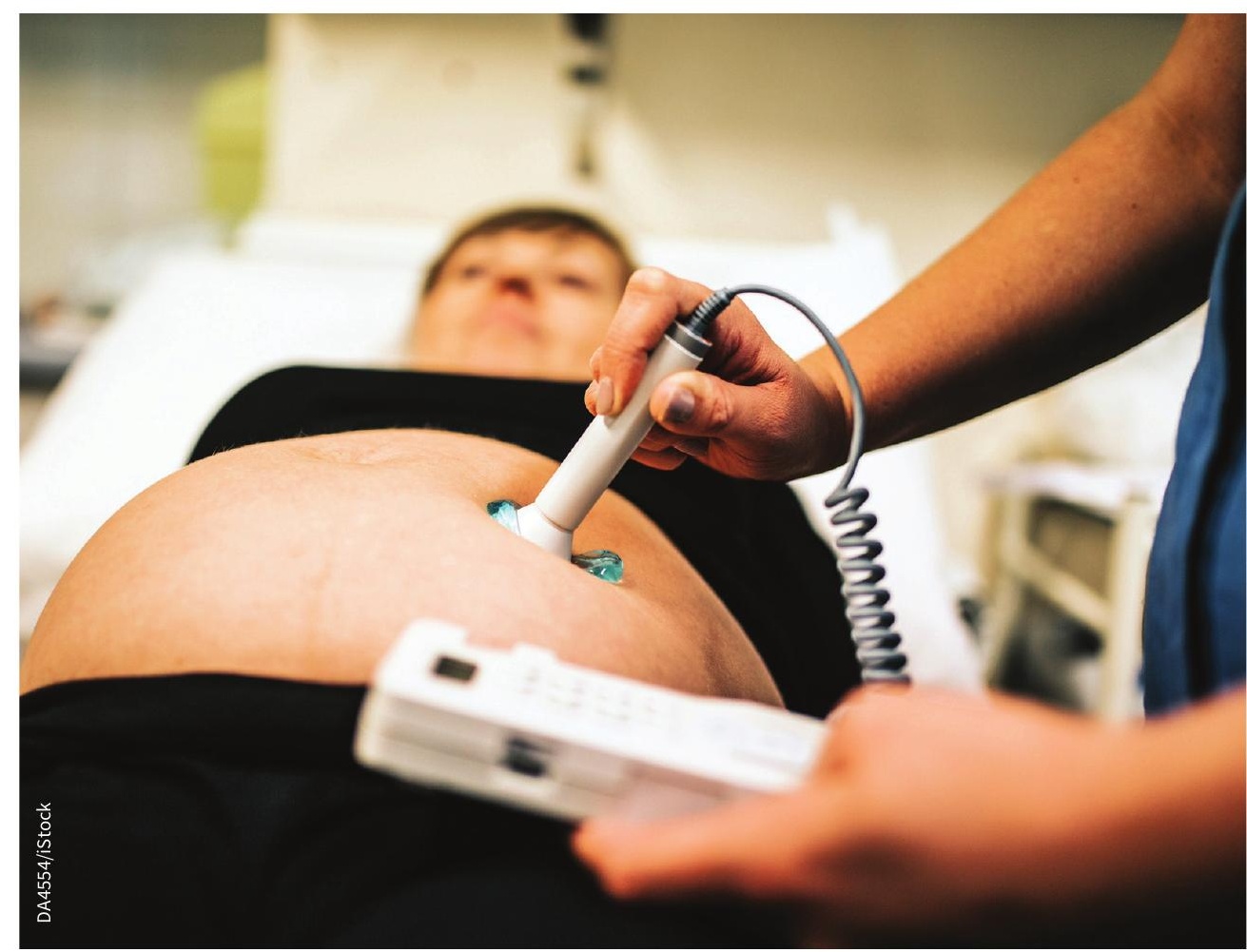

High medical liability premiums in obstetrics may make it a less desirable career choice for Canadian physicians.

According to Dr. Barbara Blumenauer of $B C$, who seconded the motion, the goal of a review by the CMA would be to ensure Canadian physicians have malpractice insurance that is comprehensive and sustainable. Malpractice litigation is one of the most stressful things physicians go through in their careers, said Blumenauer, so proper insurance is important. But premiums in certain medical disciplines have increased so much that some doctors have been forced to reduce their scope of practice or change it altogether.
"Many people don't want to do obstetrics," added Blumenauer, echoing the concerns raised by Clarke.

"We are not saying that we don't feel CMPA is the best system. We are saying we are not certain whether the models we are using in Canada are the best models available," she said. "We support looking at all available options to ensure that we have malpractice insurance that will be comprehensive and will still be there 10 , 20,30 , 40 years down the road."

Roger Collier, CMAJ 